\title{
Perspectives on Transitioning Uninsured Persons from an Emergency Department to Federally Qualified Health Centers in East Baltimore
}

\author{
Jeremy B. Lapedis, Erica H. Layer, Kiely T. Houston, Stephanie A. Levy, Meredith West, \\ Pamela J. Surkan \\ Johns Hopkins School of Public Health
}

\begin{abstract}
Many people in the United States rely on the emergency department (ED) for their usual source of primary care. Linking these ED users to a source of longitudinal primary care could provide significant health benefits. To assess an intervention attempting to connect ED users to federally qualified health cents (FQHCs), we conducted semi-structured, in-depth interviews with volunteers, health facility providers, and a patient and a focus group with program volunteers. All sessions were digitally recorded, transcribed and analyzed to develop emergent themes highlighting the barriers and facilitating factors that affect the process of connecting patients to primary care. Themes included that 1) the ED is the preferred source of primary care over FQHCs, 2) there are limited links between EDs and FQHCs and 3) the evaluated intervention acts through and depends on patients' prioritization of health and access to resources. Our findings suggest that, in addition to addressing individual needs, social services programs are well positioned to help increase communication between providers at FQHCs and EDs about both the services available to patients and patients' medical care histories.
\end{abstract}

(C) 2013 Californian Journal of Health Promotion. All rights reserved.

Keywords: Primary health care, federally qualified health center, emergency department, uninsured, qualitative

\section{Introduction}

Annual emergency department (ED) visits have been steadily increasing in the United States. In 2010, there were 25 million more visits to EDs than in 2000, while at the same time, there were 186 fewer EDs in 2010 than there were in 2000 (American College of Emergency Physicians, 2012). Over $60 \%$ of all ED visits in 2006 were for non-emergent causes (Pitts, Niska, Xu, \& Burt, 2008). The Emergency Medical Treatment and Active Labor Act (EMTALA), passed by Congress in 1986, requires that EDs provide appropriate medical treatment to any individual, regardless of citizenship, legal status, or ability to pay (Legal Information institute, 2011). Therefore, EDs are required to treat all persons who enter, whether they have an emergent condition or not.

Although it was once thought that non-urgent visits contributed to the cost of care and overcrowding in EDs, in recent years there has been significant debate about whether nonurgent visits are contributing to increasing cost of care (Bamezai, Melnick, \& Nawathe, 2005; Showstack, 2005; Williams, 1996, 2005) and whether ED overcrowding would be reduced by decreasing non-urgent visits (McCabe, 2001; Moskop, Sklar, Geiderman, Schears, \& Bookman, 2009; Schull, Kiss, \& Szalai, 2007). Nevertheless, it is still important to link nonurgent ED users to a source of primary care because patients visiting EDs for non-urgent causes are less likely to have a longitudinal relationship with a medical provider than those who visit for urgent causes (Afilalo, 2004), and there is strong evidence of improved health outcomes when the patient experiences continuity of care (Haggerty et al., 2003; Mandelblatt et al., 1999; Mark \& Paramore, 1996; O'Connor et al., 1998; Wasson et al., 1984). As many people rely on the ED for their usual source of primary care (Cunningham \& May, 2003), there could be significant health benefits to linking these people to a source of 
longitudinal primary care. Furthermore, patients with a greater continuity of care are less likely to visit the ED for a non-urgent need (Christakis, Mell, Koepsell, Zimmerman, \& Connell, 2001; Gill, Mainous, \& Nsereko, 2000; Petersen, Burstin, O’Neil, Orav, \& Brennan, 1998).

\section{Linking ED Users to a Source of Longitudinal Primary Care}

Federally qualified health centers (FQHCs) represent one potential source of longitudinal primary care for people, especially for people without insurance who are less likely to have a source of primary care (Dubay \& Kenney, 2001; Hoffman \& Paradise, 2008; Newacheck, McManus, Fox, Hung, \& Halfon, 2000; Newacheck et al., 2000; Stevens, Seid, \& Halfon, 2006). FQHCs are federally funded organizations that provide comprehensive primary, preventive, and enabling health care to designated medically underserved populations, regardless of their ability to pay (Health center programs, 2011). FQHCs have a sliding scale discount that is adjusted based on the patient's income and family size.

In trying to address inappropriate ED utilization, previous interventions which have attempted to link ED users with a source of longitudinal primary care have had varying levels of success; however, even those that were able to link ED users to a source of primary care were ultimately unsuccessful in modifying ED utilization behaviors (DeSalvo, Rest, Knight, Nettleman, \& Freer, 2000; Horwitz, Busch, Balestracci, Ellingson, \& Rawlings, 2005; McCarthy et al., 2002; Scherer \& Lewis, 2010). A systematic review of ED-based care coordination interventions found that many of these interventions have variable effectiveness (Katz, Carrier, Umscheid, \& Pines, 2012).

\section{Health Leads}

Health Leads is a non-profit organization founded in 1996 (Health leads, 2012). Health Leads mobilizes volunteer university students, in partnership with providers in urban clinics, to connect low-income patients with basic resources, such as childcare, GED classes, job training, and health insurance applications (Health leads, 2012). Health Leads currently operates in 21 sites around the country, with 1,000 volunteers serving more than 9,000 families. (Health Leads, 2012). In the spring of 2010, Health Leads began a pilot intervention of a highly focused version of its model in the ED of a Baltimore hospital. In this departure from Health Leads' typical model, volunteers focused on enrolling uninsured ED visitors in the Health Leads program with two objectives: 1) assisting Health Leads clients with applying for and obtaining insurance and 2) encouraging uninsured persons to obtain a usual source of primary care that was not the ED (typically a FQHC).

Although previous studies have sought to investigate reasons why people prefer to seek care at an ED rather than a primary care setting, there is not as much research that has been done to evaluate programs that attempt to modify this behavior (Baker, Sudano, Albert, Borawski, \& Dor, 2002; Gill, 1999; Sarver, Cydulka, \& Baker, 2002; Weber et al., 2008). To our knowledge, no studies have qualitatively examined these programs to understand the nonquantitative aspects of the interventions. As continuity of care involves both patients and providers, it is important to understand both viewpoints (Gulliford, Naithani, \& Morgan, 2006; Shepperd \& Richards, 2002). The aims of this study were 1) to understand the process of linking uninsured ED users to a usual source of care at a FQHC; 2) to gather a breadth of perspectives on the successes and challenges of an ED-based care coordination intervention; and 3) report our findings to Health Leads so they could improve their model.

\section{Methods}

In order to understand the process of an uninsured person getting from the ED to a FQHC, we conducted semi-structured, in-depth interviews with 1) Health Leads volunteers; 2) ED providers and staff; 3) Health Leads clients; and 4) FQHC providers, and a focus group with Health Leads volunteers. The study was approved by the Johns Hopkins Bloomberg School of Public Health Institutional Review Board, and all participants provided oral informed consent. 
Table 1

Characteristics of Participants

\begin{tabular}{lll}
\hline In-depth interviews & No. of participants & No. of interviews* \\
\hline Health Leads volunteers & 3 & 6 \\
ED staff & 5 & 6 \\
FQHC providers & 2 & 2 \\
Health Leads clients & 1 & 1 \\
\hline
\end{tabular}

Focus groups

\begin{tabular}{lcc} 
& No. of participants & No. of focus groups \\
\hline Health Leads volunteers & 4 & 1 \\
\hline *All Health Leads volunteers and one ED staff person were interviewed twice
\end{tabular}

\section{Participants}

Health Leads clients and volunteers and supporting staff from the ED and from FQHCs who work with Health Leads clients were purposively sampled from one ED and multiple FQHCs in Baltimore City. Participants were selected from these groups in an interactive fashion in order to provide multiple perspectives (Glaser \& Strauss, 1967; Polkinghorne, 2005) and interviews were conducted until data saturation was reached (Glaser \& Strauss, 1967) or participants could not be recruited, as discussed in the limitations section. We conducted one focus group with four Health Leads volunteers and a total of 15 in-depth interviews. Interviews were conducted with three Health Leads volunteers, five ED staff, two FQHC providers and one Health Leads client. Four participants were interviewed twice. See Table 1 for details.

\section{Procedures}

Semi-structured interview guides for in-depth interviews and focus groups included questions about interactions with uninsured persons, specific needs of uninsured persons, the process of transitioning from seeking care at an ED to a FQHC, and suggestions for improving the process. Interviewers used an open-ended approach, following up on topics that each participant discussed.

All interviews and focus groups were conducted in private locations including offices of physicians, meeting rooms at Johns Hopkins
School of Public Health, and the home of the Health Leads client. All interviewers had graduate level training in qualitative data collection and analysis. The focus group lasted approximately 60 minutes and interviews lasted between 30 and 60 minutes. All interviews were digitally recorded and then transcribed.

\section{Analysis}

Data analysis drew from grounded theory, which allows methodological analysis of inherently dynamic and interpretative interactions (Charmaz, 2006). After data were transcribed, each team member read transcripts repeatedly and coded two transcripts, line-by-line, to identify emergent themes (Charmaz, 2006). The team then met to discuss emerging themes and develop a codebook. All codes were entered into Atlas.ti 5.5. To accurately represent the data, two researchers coded each transcript and then met to resolve any differences by consensus. The research team met regularly to discuss the coding process, and new codes were added to more fully represent the data. A detailed description of the analysis process can be found in Figure 1.

\section{Results}

Participants discussed many aspects of the process of an uninsured person obtaining care at a FQHC. Many respondents emphasized reasons that patients may prefer to seek care at the ED instead of at a FQHC and how the structure of the health system influences this preference for 
Table 2

Services Offered and Access to Services at an ED and FQHC Emergency Department FQHC

\begin{tabular}{ll}
\hline $\begin{array}{l}\text { Patient/volunteer } \\
\text { perspective }\end{array}$ & \\
\hline $1 . \quad$ Quality of care & $\begin{array}{l}\text { Many tests are done and many } \\
\text { providers visit with a single patient. } \\
\text { Much attention given to patient. Stay } \\
\text { in the ED until they have an answer } \\
\text { to their health issues. }\end{array}$ \\
\hline
\end{tabular}

2. Payment method No payment up front. Patient billed after the visit.

Only see one provider. Provider may not spend much time with patient, and often must make another appointment for an answer to their health issues.

Patient required to obtain sliding-scale appointment before clinical appointment to determine payment. Payment must be made before appointment.

3. Time to get care Long waiting time before being seen, but there is no wait for an appointment once patients decide to seek care.

May not be able to get an appointment for weeks or months. Must make multiple appointments. Even with an appointment, must wait.

\begin{tabular}{|c|c|c|}
\hline $\begin{array}{l}\text { 4. Convenience of } \\
\text { care }\end{array}$ & $\begin{array}{l}\text { ED is easy to find, easy to access via } \\
\text { public transportation, and only one } \\
\text { visit is required. }\end{array}$ & $\begin{array}{l}\text { FQHC may be difficult to find } \\
\text { and inaccessible via public } \\
\text { transport. }\end{array}$ \\
\hline $\begin{array}{l}\text { 5. Perception of } \\
\text { environment }\end{array}$ & $\begin{array}{l}\text { Every person in the waiting room is } \\
\text { treated the same, and everyone must } \\
\text { wait. }\end{array}$ & $\begin{array}{l}\text { People are treated differently } \\
\text { depending on their insurance } \\
\text { status and ability to pay. }\end{array}$ \\
\hline \multicolumn{3}{|l|}{ Provider perspective } \\
\hline 1. Scope of care & $\begin{array}{l}\text { The ED treats acute, emergency } \\
\text { conditions and attempts to avoid } \\
\text { becoming a primary care source. }\end{array}$ & $\begin{array}{l}\text { FQHCs desire to be a primary, } \\
\text { longitudinal care source. }\end{array}$ \\
\hline $\begin{array}{l}\text { 2. } \begin{array}{l}\text { Access to } \\
\text { resources }\end{array}\end{array}$ & $\begin{array}{l}\text { They have access to many medical } \\
\text { tests for a variety of conditions. }\end{array}$ & $\begin{array}{l}\text { May not have access to many } \\
\text { medical tests that require } \\
\text { specific technology and have to } \\
\text { refer patients elsewhere }\end{array}$ \\
\hline $\begin{array}{l}\text { 3. Knowledge of } \\
\text { patient history }\end{array}$ & $\begin{array}{l}\text { Very little knowledge of patient } \\
\text { history. }\end{array}$ & $\begin{array}{l}\text { Would like to know patient } \\
\text { history, but do not often have } \\
\text { access to it. }\end{array}$ \\
\hline $\begin{array}{l}\text { 4. } \begin{array}{l}\text { Knowledge of } \\
\text { services to refer } \\
\text { patients }\end{array} \\
\end{array}$ & $\begin{array}{l}\text { Very little knowledge of outside } \\
\text { services. }\end{array}$ & $\begin{array}{l}\text { Some knowledge of outside } \\
\text { services, but not adequate to } \\
\text { properly inform patients. }\end{array}$ \\
\hline $\begin{array}{l}\text { 5. Time to spend } \\
\text { with patients }\end{array}$ & $\begin{array}{l}\text { Very little time to spend with } \\
\text { patients without emergency } \\
\text { conditions. }\end{array}$ & $\begin{array}{l}\text { Very little time to spend with } \\
\text { patients because of chronic } \\
\text { overscheduling. }\end{array}$ \\
\hline
\end{tabular}

ED use. Our results also highlight the ways in which the Health Leads intervention attempts to address some of these issues, and the problems volunteers face in addressing them. Three overarching themes were identified: 1) The ED is the preferred source of primary care over FQHCs; 2) there are limited links between EDs and FQHCs; and 3) the Health Leads 


\section{Figure 1}

\section{Analysis Process}

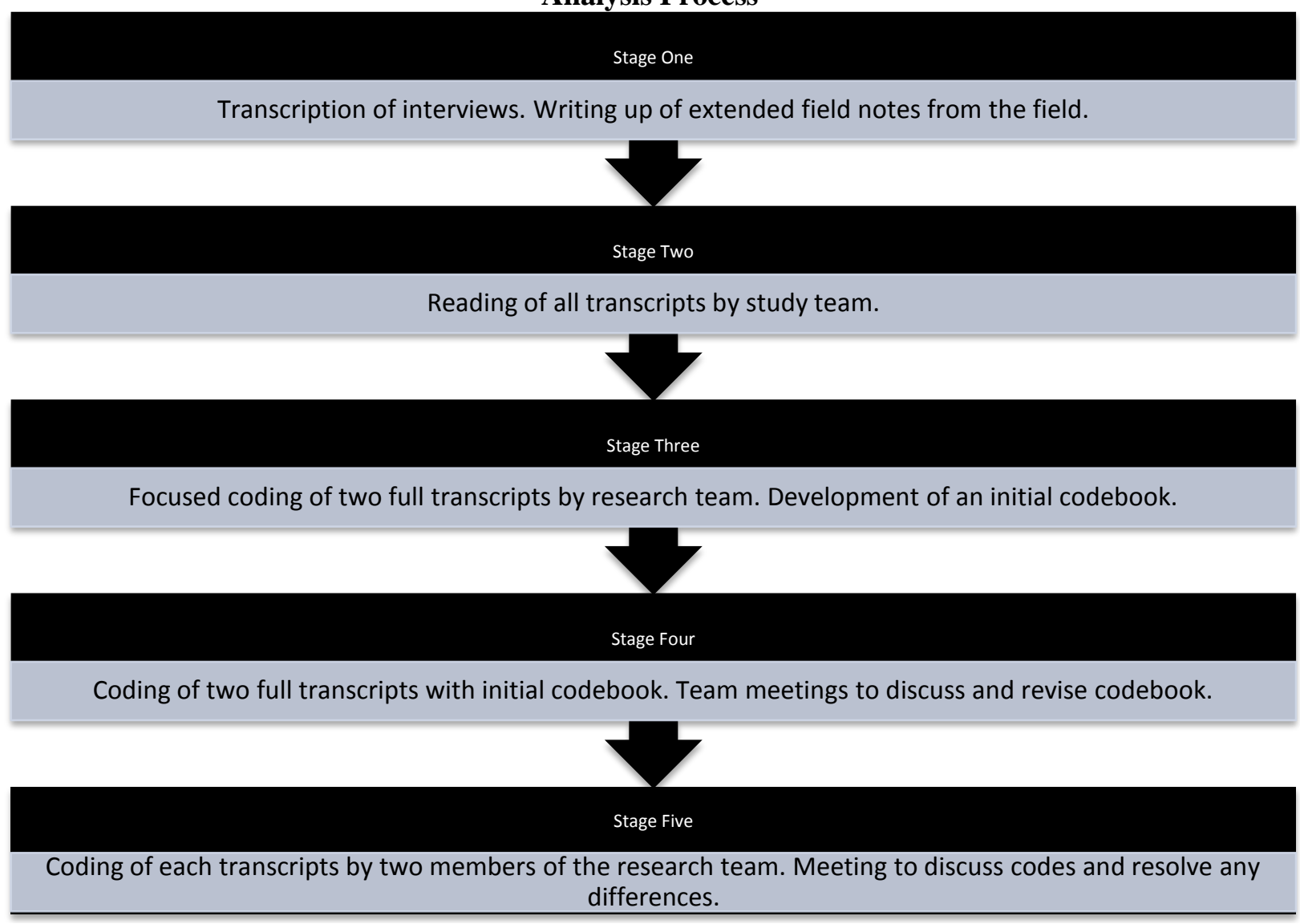

intervention acts through and depends on patients' prioritization of health and access to resources. As a summary of the first two themes, Table 2 provides a comparison of the services offered - and access to those services - at EDs and FQHCs from the patient and volunteer perspective and the provider perspective. To elucidate the process described by the participants, Figure 2 summarizes the steps to linking an uninsured ED user to an FQHC provider.

\section{The ED is Preferred as a Care Source Over FQHCs}

Perception of Care Received. Participants discussed the differences between care received in a FQHC and ED. The patient-provider interaction at FQHCs was described as often brief and limited by time constraints and the availability of services. Participants contrasted this with the sheer amount of contact a patient has with a wide variety of medical staff and physicians in the ED. The client participant also perceived having a physical examination and undergoing multiple tests at the $\mathrm{ED}$ to be indicative of high-quality care. Respondents described clear differences in the atmosphere of and treatment at the two types of care sites.

If they feel like they aren't being listened to in a clinic or if people aren't taking them seriously or if we don't give them enough time. Because we only have 15 minutes with them they might feel like they get more attention in an ER. They get their blood drawn, they usually test something in the urine... - FQHC provider

The emergency room gives off a very... positive vibe. The whole hospital does. Because you know that, no matter who you are, no matter how much people hate you or no matter if you 
can't speak English or if you have absolutely no money or anything you know you can go there... So it's a very, very comforting thing. - Health Leads volunteer

Ease of Access to Care. In addition to perception of care quality, patients' ability to access the care sites was also a factor affecting the transition process. It was frequently mentioned that a person can "just show up" at ED, without any form of payment, and be seen for their medical problems. The ED is open 24 hours a day and has fewer transportation barriers for clients. Participants also described the ED as a known entity where "all you have to do is wait for a couple of hours and you will be treated for your medical problem." ED providers emphasized the role of the ED as serving the patient, regardless of insurance status and regardless of ability to pay. All participants felt that the ED was known generally in the community for treating everyone equally and described this as a reason that patients continue to use the $\mathrm{ED}$ for regular care. As one $\mathrm{ED}$ provider explained:

In some respects the ER is a very efficient way for somebody to get a comprehensive evaluation. Something that might take days to weeks as an outpatient can be done very quickly if you discount the 8 or 10 hours that they wait to be seen. - ED provider

In contrast, Health Leads volunteers and FQHC providers described the complex planning process that is necessary to get to a FQHC. Individuals must collect numerous documents and then meet with a FQHC staff person to assess their ability to pay and be assigned a visit fee based on a sliding scale. All of this must occur before the client can make an appointment to see a provider, which also typically takes an extended period of time. Often, FQHCs are only open during typical working hours, and clients must pay for their care before seeing a provider. Many clients have difficulty navigating this process. A quote from a Health Leads volunteer exemplifies the complexities of this process:

You need a hoard of documents, like your birth certificate, social security, ID, or you need your passport, or you'll need tax forms, proof of residency, proof of income, stuff like that. And some are more demanding than others, but a lot of times they make you fill out a form before you go, and if you go there without the form or if you're missing one piece of that stuff, then you either are not seen, or you've gotta pay. -Health Leads volunteer

A lack of transportation to get to multiple FQHC appointments, the need for childcare during visits, and the safety of the neighborhood in which a FQHC is located were also mentioned as barriers to obtaining an appointment. Competing priorities such as finding safe and affordable housing, taking time off from employment, and obtaining food stamps were also commonly mentioned as barriers to care at a FQHC.

Influence of Institutional and National Policies. Health Leads volunteers and providers reported that the guidelines governing insurance policies are often difficult to negotiate, and applications are tedious. Participants also noted that making an initial appointment at a FQHC can be complicated and requires multiple visits to assess needs and ability to pay before actually being seen by a provider. Health Leads volunteers expressed that policies put in place to regulate these procedures cause frustration and confusion for their clients, which can lead to clients abandoning the process altogether. Additionally, ED providers commented that EMTALA's requirements contributed to inappropriate ED use.

\section{There Are Limited Links Between EDs and FQHCs}

Fragmentation of Care. Providers from both the ED and FQHCs described that each care site had a specific scope of care: acute emergency care and longitudinal primary care, respectively. Additionally, FQHC providers described their frustrations in being unable to meet the needs of clients who required specialty care. This fragmentation of care contributed to the difficulty of shifting patients to a regular source of care other than the ED. "By design," the care given in the ED is thorough and complete, yet 
Figure 2

\section{Process Map: Linking an Uninsured Emergency Department (ED) User to a Provider at a Federally Qualified Health Center (FQHC)}

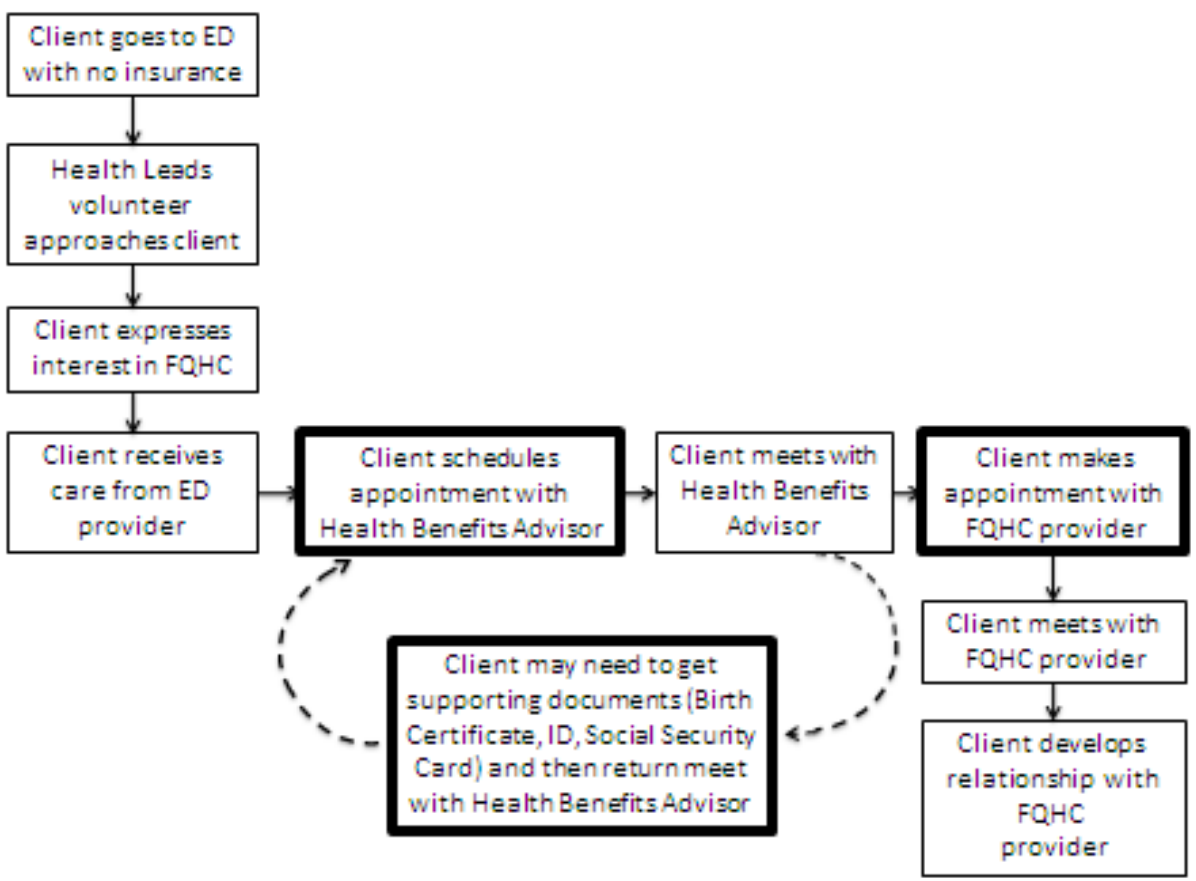

Bolded boxes indicate focus points for the Health Leads intervention

not intended to be longitudinal. ED providers will give truncated prescriptions to individuals in need of chronic care specifically to deter them from viewing the ED as a usual source of care. As one provider described:

In the emergency department we start with the assumption that this is the only time that we're going to see you, that we don't have the luxury of using time as a diagnostic or therapeutic tool, and so we really say look, the optimum ER length stay is 6 hours or less and during that time we want to figure out why you got the problem, figure out how to fix it and figure out where to send you so that you can get appropriate follow-up ... - ED Provider

In comparison, FQHCs attempt to provide longitudinal care, but do not necessarily have the resources or time to provide care for multiple problems in a single appointment. As discussed above, patients must typically make multiple appointments to address all of their concerns, making it difficult for poor patients to receive all the care that they need.

If somebody's fairly healthy and they come in with one problem, or two small problems, it's fairly easy...but often people come with multiple problems and it can be difficult to try and do everything in fifteen or twenty minutes. $-F Q H C$ Provider

Communication Across Groups. A key theme that emerged from all respondents was the lack of communication among all of the stakeholders (i.e., Health Leads, the ED, and FQHCs) involved in promoting the transition from the ED to an alternate source of regular care. This points to a commonly mentioned disconnect between the ED and the follow-up care typically provided at FQHCs. Providers at FQHCs and the ED and Health Leads volunteers described a lack of continuity in the care provided at both EDs and FQHCs. A FQHC provider described her frustrations in getting information from other 
sources of care that her patients access, including the ED:

... there's just no communication in terms of when we do have patients who we see regularly who definitely will claim us as their primary care provider, we never get communication from the doctor. Even once they get admitted we never get communication from the ER saying they were there, we never get communication from the person who worked in the hospital that took care of them while they were in the hospital. - FQHC Provider

Provider Awareness of Other Services. ED providers and staff described their lack of knowledge about FQHCs, including location, specific services provided, and sliding scale procedures for payment.

I am woefully undereducated in terms of what federally funded health centers are around Baltimore. What we have in the emergency department is basically a sheet of the local health clinics. And I don't know which ones are federally funded and which ones aren't, but that's what we refer people to when they come in ... - ED provider

\section{The Health Leads Intervention Acts Through and Depends on Patients' Prioritization of Health and Access to Resources}

Client Empowerment Through Information and Resources. Providers and Health Leads volunteers described the need to overcome disempowerment or a lack of self-efficacy in clients to motivate them to take the necessary steps to receive care at an FQHC. Health Leads volunteers, in particular, felt that part of their role was empowering clients by increasing their knowledge of available resources and promoting a sense of entitlement to primary care services.

I think a big part of it is about empowerment. I feel like a lot of people that show up at the ED for conditions that maybe aren't so emergency is because they don't feel an ownership of their health care needs, and... they don't really feel like they have the power to make decisions that could help them. So... saying [as if to Health Leads Client] "No, these are benefits that you are entitled to and we can get to the point where you actually get the necessary care that you deserve." - Health Leads volunteer

Health Leads volunteers also felt that a true measure of success was if the clients were able to "do things for themselves." In addition, providers and Health Leads volunteers felt that a lack of knowledge about various resources was a key barrier that limited the client's ability to use sources of routine care other than the ED.

Client Perception of Health as a Priority. In describing reasons that inhibited successful completion of the process, Health Leads volunteers expressed their sense that seeing a primary care provider simply was not a task to which clients wanted to devote time and energy, nor one that they recognized as important.

Also even if people think health is a high priority...if they have a job that they're going to lose if they take the time off to go to the two appointments, they're not going to go. It's like having steady income is more important to a lot of people even if they're like, "Yes, I really want to go." - Health Leads volunteer

Health Leads volunteers did note that clients with chronic conditions were more likely to perceive their own health to be a priority and therefore more likely to view finding a usual source of care as important. However, even the client participant-who had chronic back problems and successfully went to multiple appointments with a primary care provider after enrolling in the Health Leads programdescribed his desire to avoid seeking care on a regular basis:

I had no insurance my whole life. So I only went to the emergency room when I absolutely have to. If you have to go to the doctor's, then you go to the doctor's. I'm not the kind of person just to go to the doctor's to be seen. It's gotta be a must. One place you don't want to be is at a 
hospital. - Health Leads client

\section{Discussion}

The purpose of our study was to explore the various factors influencing the process of accessing primary care in a setting other than an ED by collecting perspectives from intervention volunteers, clients, and FQHC and ED staff. We found that there are many structural factors that make an ED a more attractive source of care than a FQHC, and as evidenced by our results, there are many different perspectives of what an ideal source of primary care should look like.

The Health Leads intervention addresses many influencing factors such as education and empowerment to facilitate ease of access to primary care at a $\mathrm{FQHC}$; yet, this intervention has not been sufficient to successfully assist clients in consistently accessing other sources of care. These findings are consistent with those of quantitative studies which assessed shifting primary care away from EDs towards clinics designed for longitudinal primary care (DeSalvo et al., 2000; McCarthy et al., 2002; Pitts et al., 2008; Scherer \& Lewis, 2010). In order to change where uninsured individuals seek care, it is not enough to focus on individual behaviors; attention must also be paid to the systems within which these behaviors take place.

\section{The Complexities of Establishing Longitudinal Primary Care}

A consistent theme throughout our interviews was the complexity of the process of seeing a provider at a FQHC. Uninsured persons first need to make an appointment to assess their sliding scale fee, to which they need to bring identification and proof of income. They then must make another appointment to come back on a future date to see a provider. Rust et al. (2008) found that two of the greatest barriers that cause individuals to seek care at an ED over another primary care site are that they "couldn't get through on the phone" and that they "couldn't get an appointment soon enough," findings which were supported by our interviews. The requirements at FQHCs seem to exacerbate these barriers. As described by Rust et al. (2008), these barriers illustrate the difference in "potential access" to primary care and "effective access" to primary care that uninsured individuals experience.

In contrast, as our participants noted, a person can go to an ED without prior preparation of any documents or materials and be seen on the same day. Health Leads attempts to make the process of being seen by a provider at a FQHC easier. Some Health Leads volunteers schedule appointments for clients and assist them with the acquisition of the required documents. Despite these efforts, there are limits to how much Health Leads volunteers can help with the systemic barriers that are in place.

Although policy certainly contributes to patients' preference for EDs over FQHCs and most participants mentioned that policy has an effect in the abstract, specific policies were not frequently cited. One participant, however, suggested a parallel policy to EMTALA requiring that patients be seen for non-emergent conditions at sites dedicated to primary care could have a large influence on ensuring that more uninsured persons have access to a usual source of care. There may not be much that individual programs can do to facilitate policy changes; however, a critical mass of projects that demonstrate a need for change at a policy level may influence political momentum.

\section{Opportunities for Future Interventions}

The fragmentation of care and the lack of communication between groups (i.e., FQHCs, EDs, and Health Leads) are interrelated structural issues that contribute to poor health outcomes among patients (Enthoven, 2009; Shih \& Fund, 2008). Providers at FQHCs and EDs as well as volunteers cited this as a major barrier to being able to adequately serve their patients. There was both a lack of knowledge of what services were offered by different organizations and a lack of communication between groups about those services and about individual patients. This is one area in which programs that seek to assist persons with obtaining a source of longitudinal primary care, such as Health Leads, can have a significant positive impact. These programs could facilitate the integration of a patient into a usual source of care by 
communicating with providers at both organizations about the services offered at each organization and the medical history of individual patients.

The Health Leads volunteers demonstrated significant commitment towards empowering clients at an intrapersonal level, but expressed frustration with their inability to adequately address their clients' perceptions of their own health as a priority. It has long been recognized that individuals' prioritization of health can influence compliance with a referral from an ED to a primary care setting (Jones et al., 1991; Straus, et al., 1983). Jones et al. (1991) have been able to successfully increase attendance at a follow-up appointment by intervening at the interpersonal level, but because Health Leads' model relies on volunteers with limited amounts of time to dedicate to behavioral change, it may be beyond the scope of the organization's work.

Our findings suggest that targeting uninsured persons in the ED who have chronic conditions may improve Health Leads' ability to follow up with more clients. Multiple Health Leads volunteers mentioned that they have had the most success with clients who have health issues that require longitudinal care as opposed to those with acute conditions. This is consistent with the findings of Jones et al. (1991), who found that patients with a chronic condition are more likely to attend a follow-up appointment in a primary care setting.

\section{Limitations}

Our study had several limitations. First, the indepth information obtained through qualitative methods is primarily reflective of the individual participants' experiences. While we gained a rich comprehension of the ED-to-FQHC process and were able to gather a variety of perspectives on that process in Baltimore, we recognize that our findings may not apply to different contexts. Second, in our investigation of four groups' perspectives on the ED-to-FQHC process, two groups had far fewer participants: Health Leads clients and FQHC providers. We were unable to contact and interview more than one client, which limited our ability to directly understand a client's perspective on the ED-to-FQHC process. However, this difficulty is consistent with our research findings. Health Leads volunteers repeatedly expressed the difficulties they have in contacting their clients for followup; asking for a commitment to a 30- to 40minute interview proved even more difficult. Third, the one client informant was successful in both reaching a $\mathrm{FQHC}$ for care and obtaining insurance; while his experience provided key findings on factors leading to success, his opinions and experience may differ from those held by the majority of clients. A similar argument could be made for Health Leads volunteers who participated in the study; it is possible that the Health Leads volunteers we interviewed are more active in the organization than those we did not interview.

\section{Conclusion}

In conclusion, these findings elucidate the structural barriers associated with transitioning from an ED to a FQHC as a regular source of care, and the strengths and weaknesses of programs like Health Leads to assist clients in navigating this process. Our findings draw attention to the varied, multi-level factors that affect careseeking behavior at EDs and FQHCs. Given that FQHCs are predicted to experience increased demand for services under current healthcare reform measures, it is important to understand that patients choose the ED for nonemergent conditions because they perceive the care to be higher-quality, find it easier to access care, and are unintentionally encouraged to do so by institutional and national policies (Weinkle et al., 2010). Organizations such as Health Leads may be well placed to help increase communication between key stakeholders about both the services offered and individual clients. However, many of the barriers presented in this paper will require structural changes to increase primary care visits at FQHCs. These results may also help relevant policymakers and FQHC staff to define what patient-centered care should look like in order to most effectively and efficiently address primary care needs.

\section{Acknowledgments}

Appreciation is extended to all participants for their time. The authors would like to thank 
Alexandria Appah from Health Leads for her continuous support during this project and to Aliina Hirschoff for her thoughtful manuscript critique. Caitlin Kennedy, Riina Raude, Peter
Winch, and Joel Gittelsohn also provided valuable feedback on the development of this study.

\section{REFERENCES}

Afilalo, J. (2004). Nonurgent Emergency Department Patient Characteristics and Barriers to Primary Care. Academic Emergency Medicine, 11(12), 1302-1310.

American College of Emergency Physicians. (2012). Emergency Medicine Statistical Profile. American College of Emergency Physicians.

Baker, D. W., Sudano, J. J., Albert, J. M., Borawski, E. A., and Dor, A. (2002). Loss of health insurance and the risk for a decline in self-reported health and physical functioning. Medical Care, 40(11), 1126-1131.

Bamezai, A., Melnick, G., \& Nawathe, A. (2005). The Cost of an Emergency Department Visit and Its Relationship to Emergency Department Volume. Annals of Emergency Medicine, 45(5), 483-490.

Charmaz, K. (2006). Constructing grounded theory: A practical guide through qualitative analysis. Sage Publications Ltd.

Christakis, D. A., Mell, L., Koepsell, T. D., Zimmerman, F. J., \& Connell, F. A. (2001). Association of lower continuity of care with greater risk of emergency department use and hospitalization in children. Pediatrics, 107(3), 524-529.

Cunningham, P., and May, J. (2003). Insured Americans drive surge in emergency department visits. Issue Brief (Center for Studying Health System Change), (70), 1-6.

DeSalvo, A., Rest, S. B., Knight, T., Nettleman, M., and Freer, S. (2000). Patient education and emergency room visits. Clinical Performance and Quality Healthcare, 8(1), 35-38.

Dubay, L., \& Kenney, G. M. (2001). Health Care Access And Use Among Low-Income Children: Who Fares Best? Health Affairs, 20(1), 112-121.

Enthoven, A. C. (2009). Integrated delivery systems: The cure for fragmentation. The American Journal of Managed Care, 15(10), S284-S290.

Gill, J. M. (1999). Use of hospital emergency departments for nonurgent care: A persistent problem with no easy solutions. The American Journal of Managed Care, 5(12), 1565-1568.

Gill, J. M., Mainous, A. G., 3rd, \& Nsereko, M. (2000). The effect of continuity of care on emergency department use. Archives of Family Medicine, 9(4), 333-338.

Glaser, B. G., \& Strauss, A. L. (1967). The discovery of grounded theory: Strategies for qualitative research. Aldine de Gruyter.

Gulliford, M., Naithani, S., \& Morgan, M. (2006). What is "continuity of care"? Journal of health services research \& policy, 11(4), 248-250.

Haggerty, J. L., Reid, R. J., Freeman, G. K., Starfield, B. H., Adair, C. E., \& McKendry, R. (2003). Continuity of care: a multidisciplinary review. BMJ (Clinical Research Ed.), 327(7425), 12191221.

Health center programs (2011). Available at http://bphc.hrsa.gov/ Accessed May 17, 2011.

Health Leads (2012). Available at: http://healthleadsusa.org/ Accessed June 3, 2012.

Hoffman, C., and Paradise, J. (2008). Health insurance and access to health care in the united states. Annals of the New York Academy of Sciences, 1136(Reducing the Impact of Poverty on Health and Human Development: Scientific Approaches), 149-160.

Horwitz, S. M. C., Busch, S. H., Balestracci, K., Ellingson, K. D., and Rawlings, J. (2005). Intensive intervention improves primary care Follow-up for uninsured emergency department patients. Academic Emergency Medicine, 12(7), 647-652.

Jones, S. L., Jones, P. K., and Katz, J. (1991). Compliance in acute and chronic patients receiving a health belief model intervention in the emergency department. Social Science \& Medicine, 32(10), 1183-1189. 
Katz, E. B., Carrier, E. R., Umscheid, C. A., \& Pines, J. M. (2012). Comparative Effectiveness of Care Coordination Interventions in the Emergency Department: A Systematic Review. Annals of Emergency Medicine, 60(1), 12-23.e1.

Legal Information Institute. (2011). United States Code: Title 42,1395dd. Examination and treatment for emergency medical conditions and women in labor. Available at: http://www.law.cornell.edu/uscode/42/1395dd.html. Accessed May 19, 2011

Mandelblatt, J. S., Gold, K., O’Malley, A. S., Taylor, K., Cagney, K., Hopkins, J. S., \& Kerner, J. (1999). Breast and cervix cancer screening among multiethnic women: role of age, health, and source of care. Preventive Medicine, 28(4), 418-425.

Mark, T. L., \& Paramore, L. C. (1996). Pneumococcal pneumonia and influenza vaccination: access to and use by US Hispanic Medicare beneficiaries. American Journal of Public Health, 86(11), $1545-1550$.

McCabe, J. B. (2001). Emergency department overcrowding: a national crisis. Academic Medicine: Journal of the Association of American Medical Colleges, 76(7), 672-674.

McCarthy, M. L., Hirshon, J. M., Ruggles, R. L., Docimo, A. B., Welinsky, M., and Bessman, E. S. (2002). Referral of medically uninsured emergency department patients to primary care. Academic Emergency Medicine, 9(6), 639-642.

Moskop, J. C., Sklar, D. P., Geiderman, J. M., Schears, R. M., \& Bookman, K. J. (2009). Emergency Department Crowding, Part 1 - Concept, Causes, and Moral Consequences. Annals of Emergency Medicine, 53(5), 605-611.

Newacheck, P. W., McManus, M., Fox, H. B., Hung, Y.-Y., \& Halfon, N. (2000). Access to Health Care for Children With Special Health Care Needs. Pediatrics, 105(4), 760-766.

O’Connor, P. J., Desai, J., Rush, W. A., Cherney, L. M., Solberg, L. I., \& Bishop, D. B. (1998). Is having a regular provider of diabetes care related to intensity of care and glycemic control? The Journal of Family Practice, 47(4), 290-297.

Petersen, L. A., Burstin, H. R., O’Neil, A. C., Orav, E. J., \& Brennan, T. A. (1998). Nonurgent emergency department visits: the effect of having a regular doctor. Medical Care, 36(8), 12491255.

Pitts, S. R., Niska, R. W., Xu, J., and Burt, C. W. (2008). National hospital ambulatory medical care survey: 2006 emergency department summary. Natl Health Stat Report, 7(7), 1-38.

Polkinghorne, D. E. (2005). Language and Meaning: Data Collection in Qualitative Research. Journal of Counseling Psychology, 52(2), 137-145.

Rust, G., Ye, J., Baltrus, P., Daniels, E., Adesunloye, B., and Fryer, G. E. (2008). Practical barriers to timely primary care access: Impact on adult use of emergency department services. Archives of Internal Medicine, 168(15), 1705-1710.

Sarver, J. H., Cydulka, R. K., and Baker, D. W. (2002). Usual source of care and nonurgent emergency department use. Academic Emergency Medicine, 9(9), 916-923.

Scherer, T. M., and Lewis, L. M. (2010). Follow-up to a federally qualified health center and subsequent emergency department utilization. Academic Emergency Medicine, 17(1), 55-62.

Shih, A., and Fund, C. (2008). Organizing the US health care delivery system for high performance. Commonwealth Fund.

Schull, M. J., Kiss, A., \& Szalai, J.-P. (2007). The effect of low-complexity patients on emergency department waiting times. Annals of Emergency Medicine, 49(3), 257-264.

Shepperd, S., \& Richards, S. (2002). Continuity of care -- a chameleon concept. Journal of health services research \& policy, 7(3), 130-132.

Showstack, J. (2005). The Costs of Providing Nonurgent Care in Emergency Departments. Annals of Emergency Medicine, 45(5), 493-494.

Stevens, G. D., Seid, M., \& Halfon, N. (2006). Enrolling vulnerable, uninsured but eligible children in public health insurance: association with health status and primary care access. Pediatrics, 117(4), e751-e759. 
Straus, J. H., Orr, S. T., and Charney, E. (1983). Referrals from an emergency room to primary care practices at an urban hospital. American Journal of Public Health, 73(1), 57.

Wasson, J. H., Sauvigne, A. E., Mogielnicki, R. P., Frey, W. G., Sox, C. H., Gaudette, C., \& Rockwell, A. (1984). Continuity of outpatient medical care in elderly men. A randomized trial. JAMA: The Journal of the American Medical Association, 252(17), 2413-2417.

Weber, E. J., Showstack, J. A., Hunt, K. A., Colby, D. C., Grimes, B., Bacchetti, P., and Callaham, M. L. (2008). Are the uninsured responsible for the increase in emergency department visits in the United States? Annals of Emergency Medicine, 52(2), 108-115.

Weinkle, J., Feinstein, K. W., and Kanel, K. (2010). Analysis \& Commentary partnering private primary care practices with federally qualified health centers in the care of complex patients. Health Affairs, 29(6), 1211-1213.

Williams, R. M. (1996). The Costs of Visits to Emergency Departments. New England Journal of Medicine, 334(10), 642-646.

Williams, R. M. (2005). The costs of visits to emergency departments--revisited. Annals of Emergency Medicine, 46(5), 471-472; author reply 472-473.

\section{Author Information}

*Jeremy B. Lapedis, MSPH

Johns Hopkins School of Public Health

Department of International Health

615 N. Wolfe St.

Baltimore, MD, 21205

Email: jlapedis@jhsph.edu

Telephone: (617) 450-1047

Erica H. Layer, MSPH

Johns Hopkins School of Public Health

Department of International Health

Kiely T. Houston, MSPH

Johns Hopkins School of Public Health

Department of International Health

Stephanie A. Levy, MSPH

Johns Hopkins School of Public Health

Department of International Health

Meredith West, MSPH

Johns Hopkins School of Public Health

Department of International Health

Pamela J. Surkan, ScD

Johns Hopkins School of Public Health

Department of International Health

* corresponding author 